\title{
Axon Guidance Proteins: A Novel Target Point for Temporal Lobe Epilepsy
}

\author{
Sajad Sahab Negah ${ }^{1,2 *}$, Ali Jahanbazi Jahan-Abad², Sayed Mostafa Modarres Mousavi ${ }^{2,3}$ \\ ${ }^{1}$ Department of Neuroscience, Faculty of Medicine, Mashhad University of Medical Sciences, Mashhad, Iran \\ ${ }^{2}$ Shefa Neuroscience Research Center, Khatam Alanbia Hospital, Tehran, Iran \\ ${ }^{3}$ Department of Nanobiotechnology, Faculty of Biological Sciences, Tarbiat Modares University, Tehran, Iran
}

\section{ABSTRACT}

Introduction: Epilepsy is primarily a neuronal network disorder characterized by recurrent and unpredictable seizures. Epilepsy is not only characterized by marked changes in ion channels but also by the abnormal synaptic protein expression. It has been reported that the expression of axon guidance proteins was changed in experimental models of epilepsy. In this letter to the editor, we review and discuss the changes of axon guidance proteins in epilepsy. Conclusion: Collectively, further insight into dysregulation of axon guidance proteins may help to develop novel therapeutic strategies for epilepsy.

*Corresponding Author: Sajad Sahab Negah

E-mail:sahabnegahs@mums.ac.ir 
يروتئينهاى هدايت آكسونى: هدف درمانى جديد براى صرع لوب گيجعَاهى

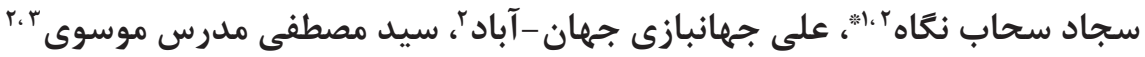 \\ اكروه علوم اعصاب، دانشكده يزشكى، دانشعاه علوم يزشكى مشهد، مشهد، ايران \\ 'مركز تحقيقات علوم اعصاب شفا، بيمارستان خاتمالانبياء، تهران، ايران \\ "كروه نانوبيوتكنولوزى، دانشكده علوم زيستى، دانشخاه تربيت مدرس، تهران، ايران
}

\title{
اطلاعات مقاله:
}

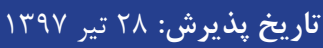

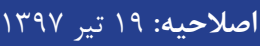

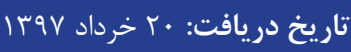

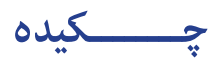

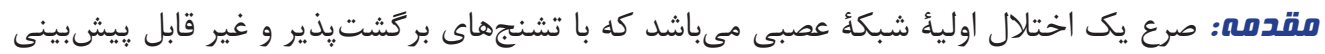

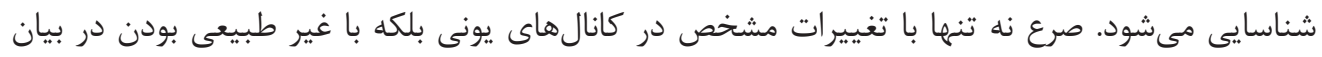

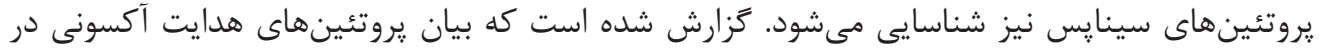

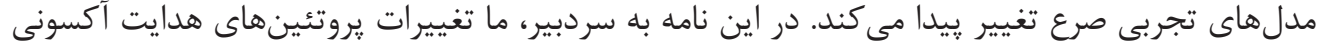

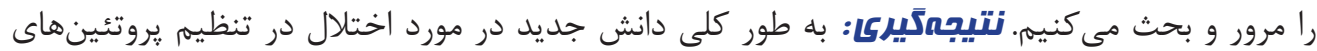

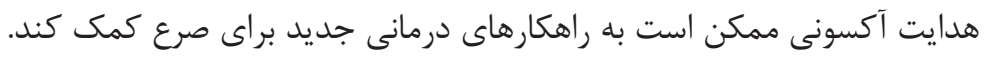

\footnotetext{
كليد وازهها:

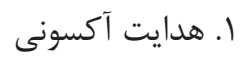

r

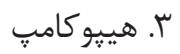

" نويسنده مسئول: سجاد سحاب نعاه آدرس الكترونيكى: sahabnegahs@mums.ac.ir 


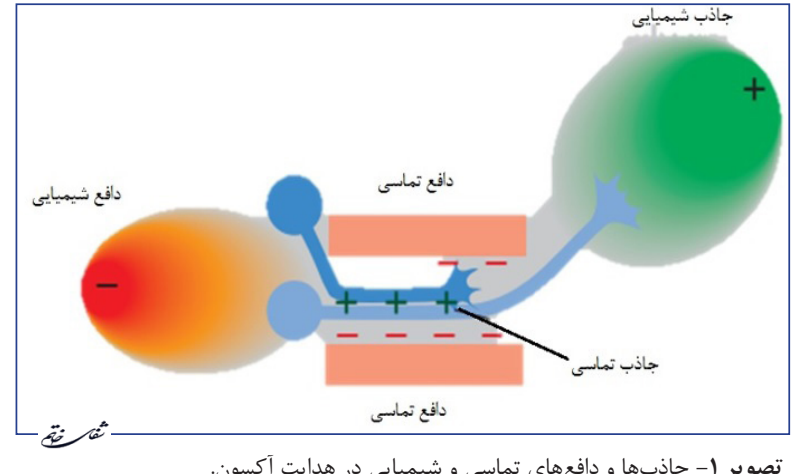

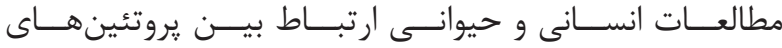

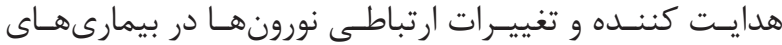

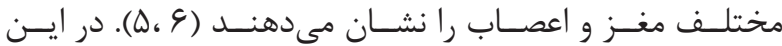

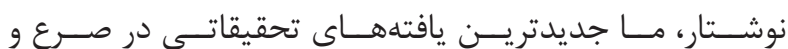

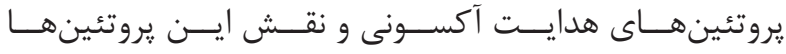

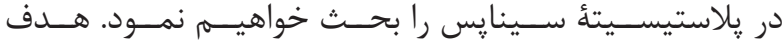

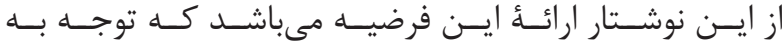

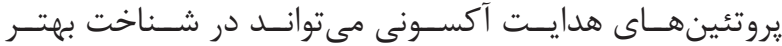

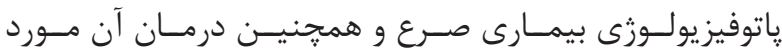

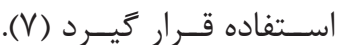

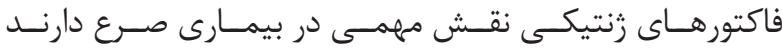

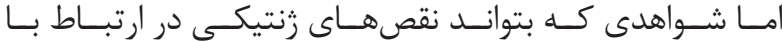

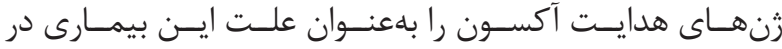

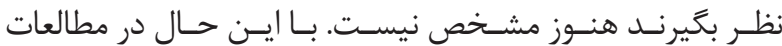

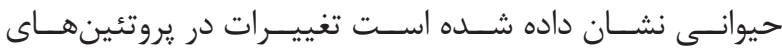

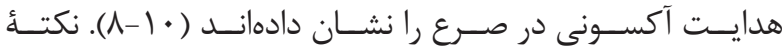

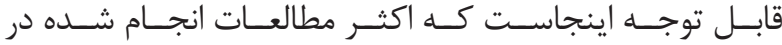

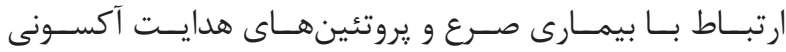

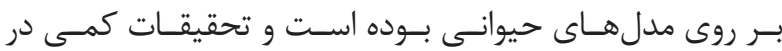

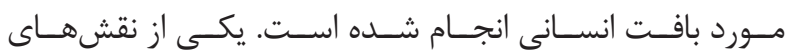

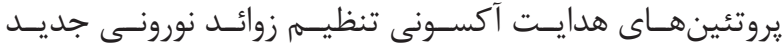

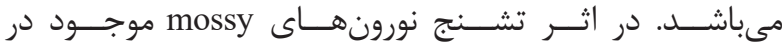

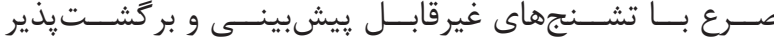

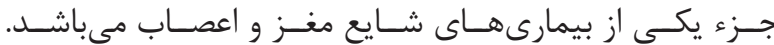

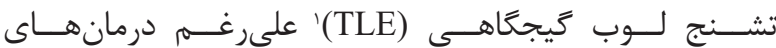

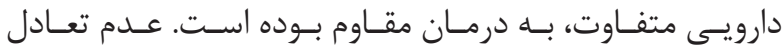

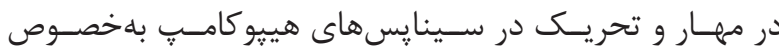

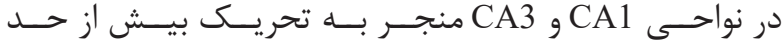

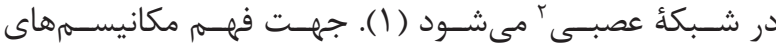

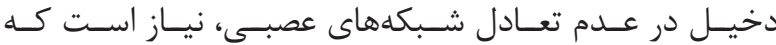

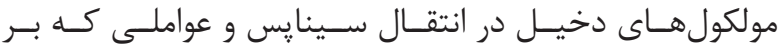

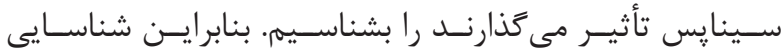

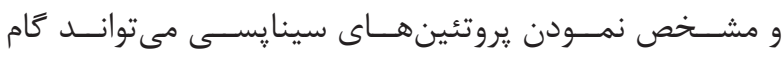

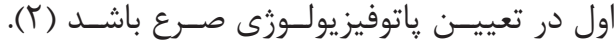

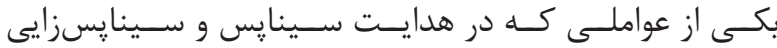

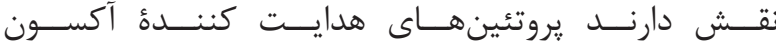

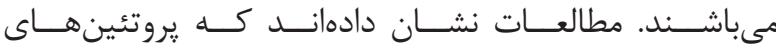

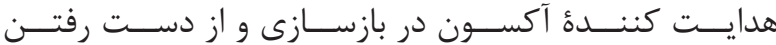

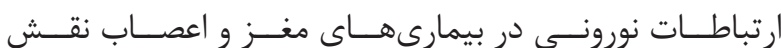

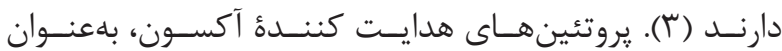

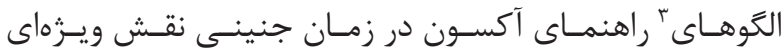

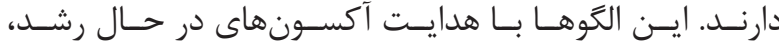

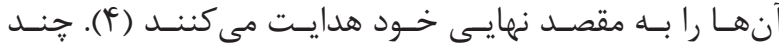

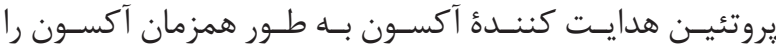

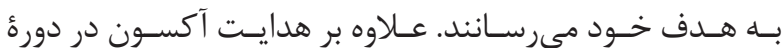

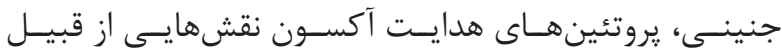

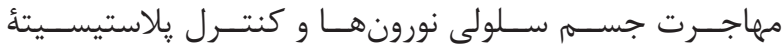

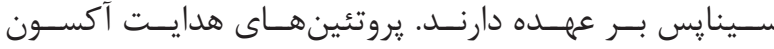

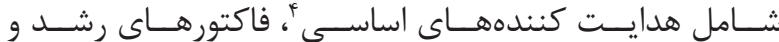

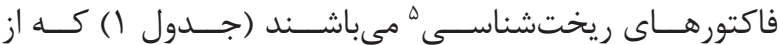

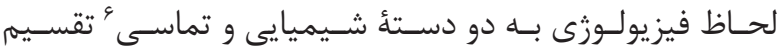

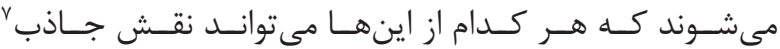

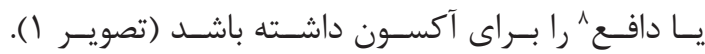

جدول ا- مولكولهاى دخيل در هدايت آكسونى.

\begin{tabular}{|c|c|c|c|}
\hline نقش در هدايت آكسون & يرنده & الخوها & نام هدايت كننده \\
\hline جاذب & DCCs & \multirow{2}{*}{ نترينها" } & \multirow{6}{*}{ هدايت كنندههاى اساسى } \\
\hline دافع & UNC-5s & & \\
\hline دافع & Plexins & \multirow{2}{*}{ سمافورينها } & \\
\hline دافع & Neuropilins & & \\
\hline دافع & Robos & 'اسليتها' ' & \\
\hline جاذب و دافع & Eph-As, Bs & افرينها & \\
\hline جاذب و دافع & Frizzled & Wnt & \multirow{3}{*}{ مورفوزنزها } \\
\hline جاذب & Boc and smoothened & Hedgehog & \\
\hline دافع & BMPRs & Bmps & \\
\hline 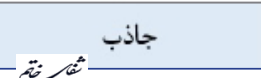 & GFR $\alpha$, FGFR, Met, trks & $\begin{array}{l}\text { GDNF, FGF, HGF, } \\
\text { Neurotrophin }\end{array}$ & فاكتورهاى رشد \\
\hline
\end{tabular}

${ }^{1}$ Temporal lobe epilepsy

${ }^{2}$ Neuronal network

${ }^{3}$ Cues

${ }^{4}$ Canonical

${ }^{5}$ Morphology
${ }^{6}$ Contact

${ }^{7}$ Attractant

${ }^{8}$ Repulsion

${ }^{9}$ Netrins

${ }^{10}$ Slits 
مانـــ CA1 و CA3 تنظيـهم مى كنــــد و نشـان داده شـده اسـت

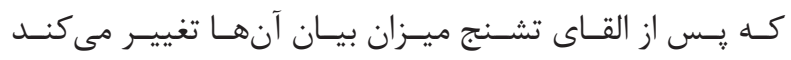

$$
\text { نتيجه كيرى }
$$

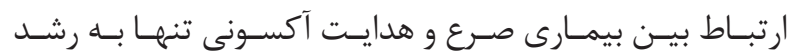

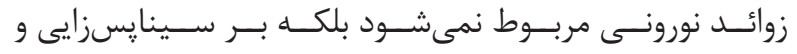

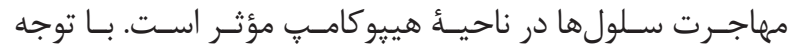

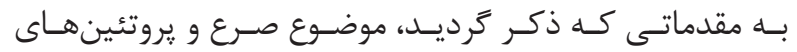

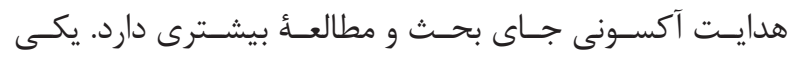

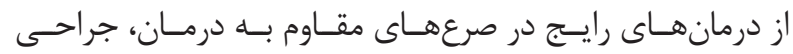

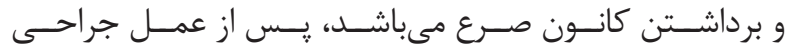

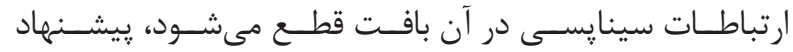

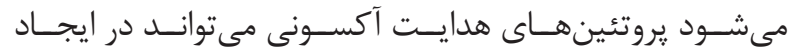

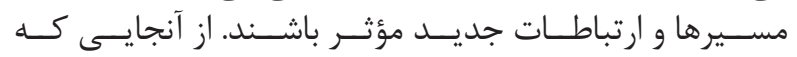

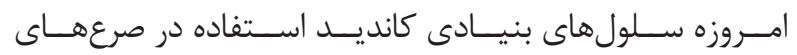

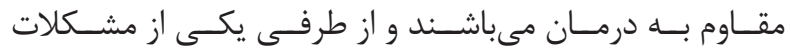

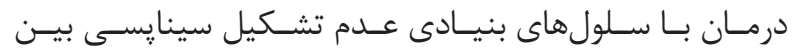

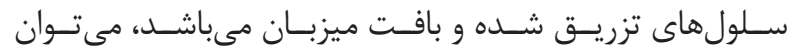

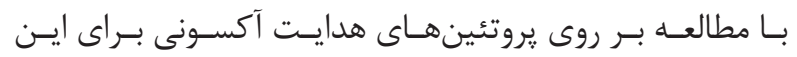

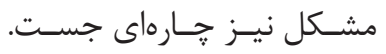

1. Morelli E, Ghiglieri V, Pendolino V, Bagetta V, Pignataro A, Fejtova A, et al. Environmental enrichment restores CA1 hippocampal LTP and reduces severity of seizures in epileptic mice. Exp Neurol. 2014; 261: 320-7.

2. Fukata Y, Fukata M. Epilepsy and synaptic proteins. Current Opinion in Neurobiology. 2017; 45 :1-8.

3. Lin L, Lesnick TG, Maraganore DM, Isacson O. Axon guidance and synaptic maintenance: preclinical markers for neurodegenerative disease and therapeutics. Trends in Neurosciences. 2009; 32(3): 142-9.

4. Kolodkin AL, Tessier-Lavigne M. Mechanisms and molecules of neuronal wiring: a primer. Cold Spring Harbor Perspectives in Biology. 2011; 3(6): 1-15.

5. Izzi L, Charron F. Midline axon guidance and human genetic disorders. Clinical Genetics. 2011; 80(3): 226-34.

6. Nugent AA, Kolpak AL, Engle EC. Human disorders of axon guidance. Current Opinion in Neurobiology. 2012; 22(5): 837-43.

7. Van Battum EY, Brignani S, Pasterkamp RJ. Axon guidance proteins in neurological disorders. The Lancet Neurology. 2015; 14(5): 532-46.

8. Xia Y, Luo C, Dai S, Yao D. Increased EphA/ephrinA expression in hippocampus of pilocarpine treated mouse. Epilepsy Res. 2013; 105(1-2): 20-9.

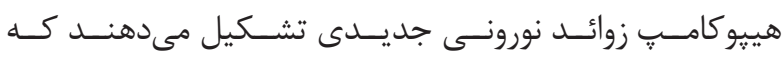

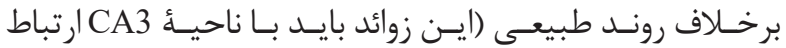

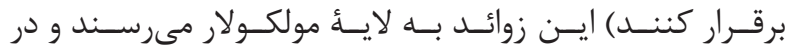

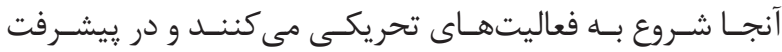

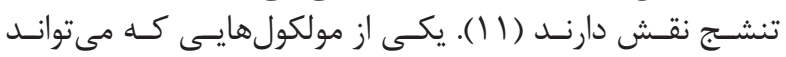

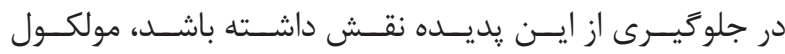

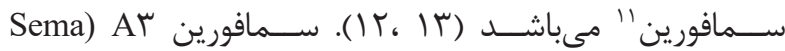

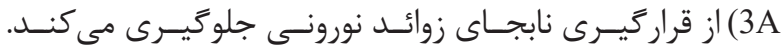

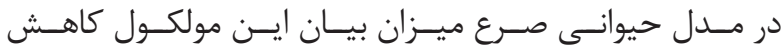

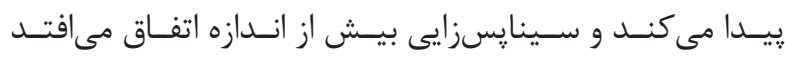

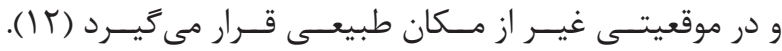

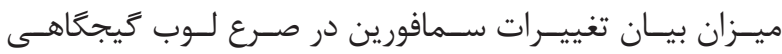

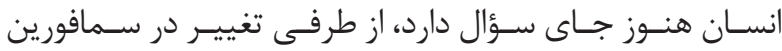

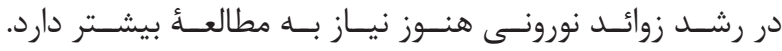

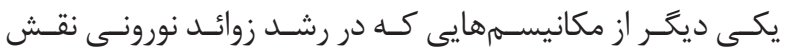

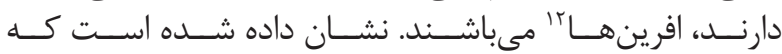

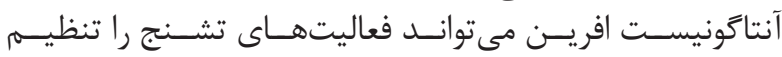

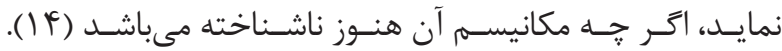

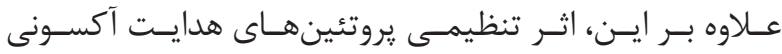

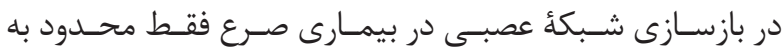

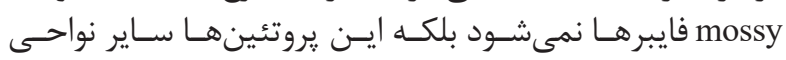

منابع

9. Fang M, Liu GW, Pan YM, Shen L, Li CS, Xi ZQ, et al. Abnormal expression and spatiotemporal change of Slit2 in neurons and astrocytes in temporal lobe epileptic foci: a study of epileptic patients and experimental animals. Brain Res. 2010; 1324: 14-23.

10. Koyama R, Ikegaya Y. Mossy fiber sprouting as a potential therapeutic target for epilepsy. Curr Neurovasc Res. 2004; 1(1): 3-10.

11. Babb TL, Pretorius JK, Mello LE, Mathern GW, Levesque MF. Synaptic reorganizations in epileptic human and rat kainate hippocampus may contribute to feedback and feedforward excitation. Epilepsy Res Suppl. 1992; 9: 193-202.

12. Holtmaat AJ, Gorter JA, De Wit J, Tolner EA, Spijker $\mathrm{S}$, Giger RJ, et al. Transient downregulation of Sema3A mRNA in a rat model for temporal lobe epilepsy. a novel molecular event potentially contributing to mossy fiber sprouting. Exp Neurol. 2003; 182(1): 142-50.

13. Barnes G, Puranam RS, Luo Y, McNamara JO. Temporal specific patterns of semaphorin gene expression in rat brain after kainic acid-induced status epilepticus. Hippocampus. 2003; 13(1): 1-20.

14. Saffarzadeh F, Eslamizade MJ, Ghadiri T, Modarres Mousavi SM, Hadjighassem M, Gorji A. Effects of TRPV1 on the hippocampal synaptic plasticity in the epileptic rat brain. Synapse. 2015; 69(7): 375-83.

\footnotetext{
${ }^{11}$ Semaphorin

${ }^{12}$ Ephrins
} 